\section{Misplaced faith}

\section{The public trusts scientists much more than scientists think. But should it?}

$\mathrm{B}$ ritish chemists are a diffident and self-conscious bunch. A poll by the Royal Society of Chemistry (RSC) has revealed that its members are pessimistic about their status in society. The general public, said the chemists, thinks that chemistry is boring and of little value. Worse, they said, the public thinks chemists are unapproachable. Such negative views have shaped the way that British chemists have promoted themselves and their research; they have focused on counteracting a negative and damaging stereotype about chemistry and chemicals.

Yet as RSC science communicator Chiara Ceci writes in a World View on page 7 , the British public does not think these things at all. In another part of the poll, most members of the public were generally positive about chemistry, if a little hazy on its specific benefits and exactly what chemists do. The strongest reaction to the central science was not fear or confusion, but simple indifference. That can be useful. It creates what public-relations experts call a void in the collective consciousness - one that they can fill with positive images.

If the British public likes chemistry - at least more than the chemists believed - then it is positively glowing about science in general. Survey respondents described it with words such as 'welcoming', 'sociable' and 'fun'. And a separate poll by Ipsos MORI this year showed that scientists are among the most trusted professionals in Britain; some nine in ten people said that they trust scientists to follow all of the research rules and regulations relevant to them.

How many scientists would say the same? Not many, probably, of the attendees at this week's 4th World Conference on Research Integrity in Rio de Janeiro, Brazil. As we report on page 14, attendees at the weekend discussed the latest high-profile case of scandal, fraud allegations and retraction. The attention drawn by the paper in question - discussing how views on same-sex marriage can be changed - prompted The New York Times to publish an editorial titled 'Scientists who cheat'. That will not help to fill any void with positive images.

Some scientists do cheat, of course, just as some scientists drive too fast, take drugs and are unfaithful to their spouses. The reasons are complex and varied. With some exceptions, scientific organizations
"Nine inten scientists to follow the rules. How many scientists would say the same?" people trust do not engage with the issue of misconduct as seriously as they should. Why would they, when public confidence and (moral and financial) support remains so high?

Media coverage of the same-sex-marriage retraction was laced with portentous language, claiming that faith and trust in science had been profoundly shaken. Yet, as researchers who follow misconduct issues will know, faith and trust in science have survived worse in recent years.

That should not be taken as an excuse to ignore the problem of research misconduct or to minimize its importance. And although highprofile fraud makes headlines, a broader and more common set of unappealing behaviours - from corner-cutting to data-juggling - lie under the surface. Convention says that a tiny minority of scientists cheats, yet academics and researchers frequently make the case that irregularities are widespread. A 2014 survey of hundreds of economists, for example, found that $94 \%$ admitted to having engaged in at least one "unaccepted" research practice (S. Necker Res. Policy 43, 1747-1759; 2014).

Just like with British chemistry, it seems that the wider public's view of science and research is rosier than that of many people who are directly involved. For how long can this continue?

\section{To Pluto}

\section{The coming months promise to shed new light on the Solar System's underworld.}

$\mathrm{P}$ luto has always had something of a raw deal. In classical mythology, while Zeus got sovereignty of heaven and Poseidon mastery of the seas, their brother Pluto (former name, Hades) was lumbered with the underworld and its legions of the dead. Pluto the planet had its discovery delayed by a decade-long legal battle, and then barely made it into the textbooks of the twenty-first century before astronomers decided to strip away its full planetary status. Its classification of dwarf planet is still contested by some. To others, it is the first example of the plutoid category of trans-Neptunian objects.

And then there are its moons. When the fourth of Pluto's satellites was discovered in 2011, a campaign headed by Star Trek actor William Shatner proposed the name Vulcan. Preferring to maintain the underworld theme, astronomers chose Cerberus, after the dominion's threeheaded guard dog - although because that is already the name of an asteroid, they had to settle on the Greek spelling, Kerberos.

The other minor moons, Styx (gloomy river and one-time plunge pool for the infant Achilles), Hydra (many-headed serpentine sentinel) and Nix (a variant spelling of Nyx, goddess of the night) are joined by a large moon about half the size of Pluto called Charon (ferryman of the Styx and son of Nyx). Charon, some astronomers say, forms with Pluto the Solar System's only binary planet. Or perhaps that should be double plutoid system.

In other words, nothing about this corner of our Solar System has been straightforward. And as the NASA spacecraft New Horizons hurtles towards it for the first close-up look at these bodies, astronomers this week pose new questions about the heavenly body formerly known as the planet Pluto. The answers, some of which might come when New Horizons flies past the dwarf planet in mid-July, could help researchers to understand how planets and their moons form in the first place.

Little is known about Pluto's creation, but astronomers had assumed that it formed from the remains of a collision between proto-Pluto and a proto-Charon. The smaller moons may have then come together from bits among the swirling impact debris. The 2012 discovery of Styx was already something of a surprise, because studies had suggested the other three smaller moons were packed so closely together that there was no room for another.

On page 45 of this issue, planetary scientists Mark Showalter and Douglas Hamilton describe how they analysed Hubble Space Telescope images to build up a picture of the orbital configurations and brightnesses of Pluto's small moons. They find that Styx, Nix and Hydra are locked together in what astronomers call three-body resonance, a phenomenon that links the timing of their orbits and usually makes their movements stable.

They also suggest that Kerberos is a little out of place. Although Nix and Hydra have bright surfaces similar to that of Charon, Kerberos appears as dark as coal, and this raises questions about how this mixed satellite system might have formed. (Pluto is the brightest of the lot, with a reflectivity roughly that of sea ice.) Their findings are discussed in a News $\&$ Views article on page 40 .

The mythological name of Hades for the god of the underworld was replaced because Pluto has a more positive spin: it associ-
DNATURE.COM To comment online, click on Editorials at: go.nature.com/xhunqv ated the ruler with the mineral wealth found underground. The next few weeks promise a revival of interest in Pluto, and a polishing of its image too. It deserves its time in the (dim and distant) Sun. 